\title{
Pyloric Gland Adenoma of the Esophagus Treated by Endoscopic Submucosal Dissection: A Case Report
}

\author{
Kwangbeom Park', Do Hoon Kim¹, Sung Duck Lee', Hyun Lee², and Hwoon-Yong Jung ${ }^{1}$ \\ Departments of ${ }^{1}$ Gastroenterology and ${ }^{2}$ Pathology, Asan Medical Center, University of Ulsan College of Medicine, Seoul, Korea
}

\author{
Article Info \\ Received August 5, 2021 \\ Revised October 26, 2021 \\ Accepted November 12, 2021 \\ Published online February 11, 2022 \\ Corresponding Author \\ Do Hoon Kim \\ ORCID https://orcid.org/0000-0002-4250-4683 \\ E-mail dohoon.md@gmail.com
}

\begin{abstract}
A pyloric gland adenoma is a rare neoplasm that occurs most frequently in the stomach and should be removed because of its precancerous potential. Although there have been case reports of pyloric gland adenomas in extragastric areas such as the duodenum, pancreas, and bile duct, esophageal pyloric gland adenoma has never been reported in Korea. Herein, we report a case of esophageal pyloric gland adenoma that was successfully treated by endoscopic submucosal dissection. (Gut Liver 2022;16:483-486)
\end{abstract}

Key Words: Pyloric gland adenoma; Endoscopic submucosal dissection; Esophagus; Case reports

\section{INTRODUCTION}

A pyloric gland adenoma is a rare neoplasm, mostly diagnosed in the stomach. It is a precancerous lesion with a transformation rate to adenocarcinoma of $12 \%$ to $47 \%$. Although most cases are observed in the stomach, there are some case reports of pyloric gland adenomas arising in the duodenum, ${ }^{2}$ pancreas, ${ }^{3}$ gallbladder, ${ }^{4}$ and uterine cervix. ${ }^{5}$ While several cases of pyloric gland adenomas in the esophagus have also been reported, ${ }^{6-8}$ none have been in Korea. Herein, we report a case of a pyloric gland adenoma of the esophagus that was treated by endoscopic submucosal dissection. Informed consent was obtained.

\section{CASE REPORT}

An 86-year-old man with symptoms of reflux underwent upper endoscopy at an outside hospital. Endoscopy showed a flat, elevated lesion on his upper esophagus. The biopsy revealed a pyloric gland adenoma. He had hypertension, benign prostate hypertrophy, and a history of coil embolization for a cerebral aneurysm. The laboratory findings, including complete blood count, as well as liver function test and electrolyte and serum creatinine measurements, were normal. Upper endoscopy revealed a 1.2-cm-sized oval-shaped, flat elevated lesion with a nodular surface located $20 \mathrm{~cm}$ from the upper incisor teeth (Fig. $1 \mathrm{~A}$ and $\mathrm{B})$. Atrophic changes were visible in the antrum of the stomach and accompanied by multiple $1-3 \mathrm{~mm}$ sized, translucent, round, and smooth surfaced polyps on the fundus and the body of the stomach. Abnormal findings were not observed in the duodenum. A computed tomography scan of the chest revealed reactive lymph nodes among the subcarinal, subaortic, and right lower paratracheal lymph nodes. Endoscopic ultrasonography showed a hypoechoic lesion confined to the mucosal layer (Fig. 1C). A biopsy showed a pyloric gland adenoma with low grade dysplasia. The lesion was removed by endoscopic submucosal dissection (Fig. 2). Since the Lugol-void lesion was confined to the mucosal layer of the esophagus, the submucosal dissection of the pyloric gland adenoma was uncomplicated. The resected specimen size measured $2.0 \times 1.4 \times 0.3 \mathrm{~cm}$ and the tumor size was $1.1 \times 0.6 \times 0.2 \mathrm{~cm}$. Immunohistochemical analysis showed that the specimen was immunopositive for MUC6 (a pyloric gland mucin marker) and MUC5AC (a foveolar mucin marker). The specimen was also positive for p53 (intensity $2+$ ) and the Ki-67 level was $10 \%$ to $20 \%$. The final pathology result was a pyloric gland adenoma with high-grade dysplasia and the resection margin was clear (Fig. 3). 

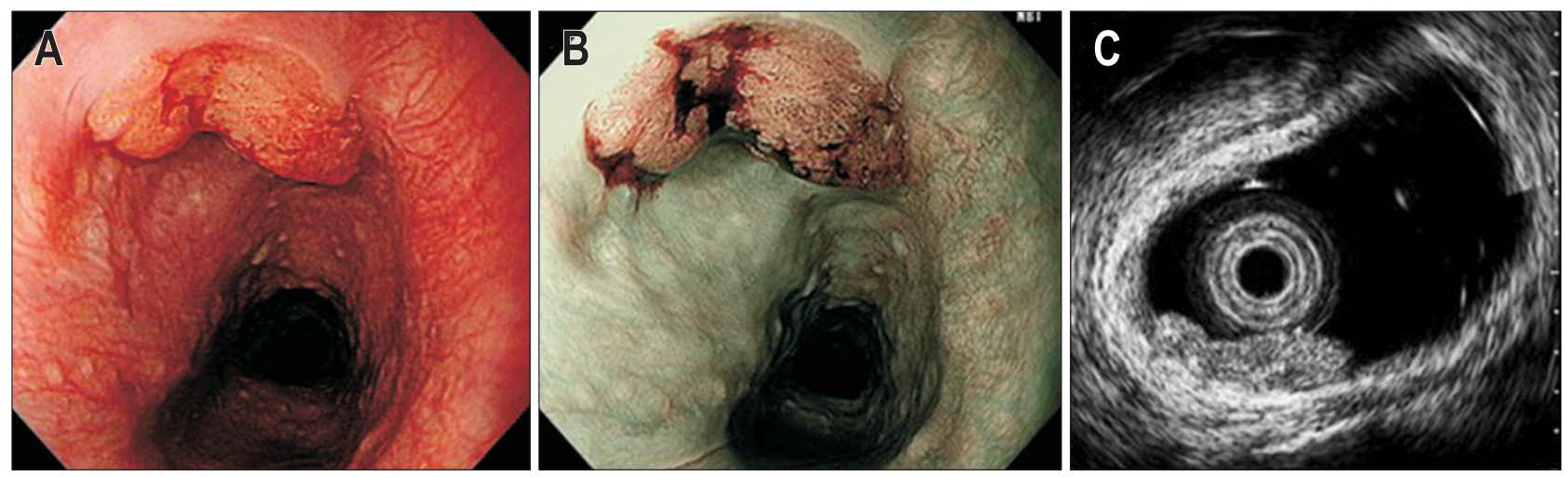

Fig. 1. Endoscopic findings of the esophageal pyloric gland adenoma. (A) White-light endoscopy showing a 1.2-cm, oval-shaped, flat, elevated lesion with nodularity located $20 \mathrm{~cm}$ from the upper incisor teeth. (B) Narrow-band imaging showing the brownish color change in the lesion with a gyrus-forming pattern in the background of normal-appearing esophageal mucosa. (C) Endoscopic ultrasonography showing a homogenous, hypoechoic lesion confined to the mucosal layer.
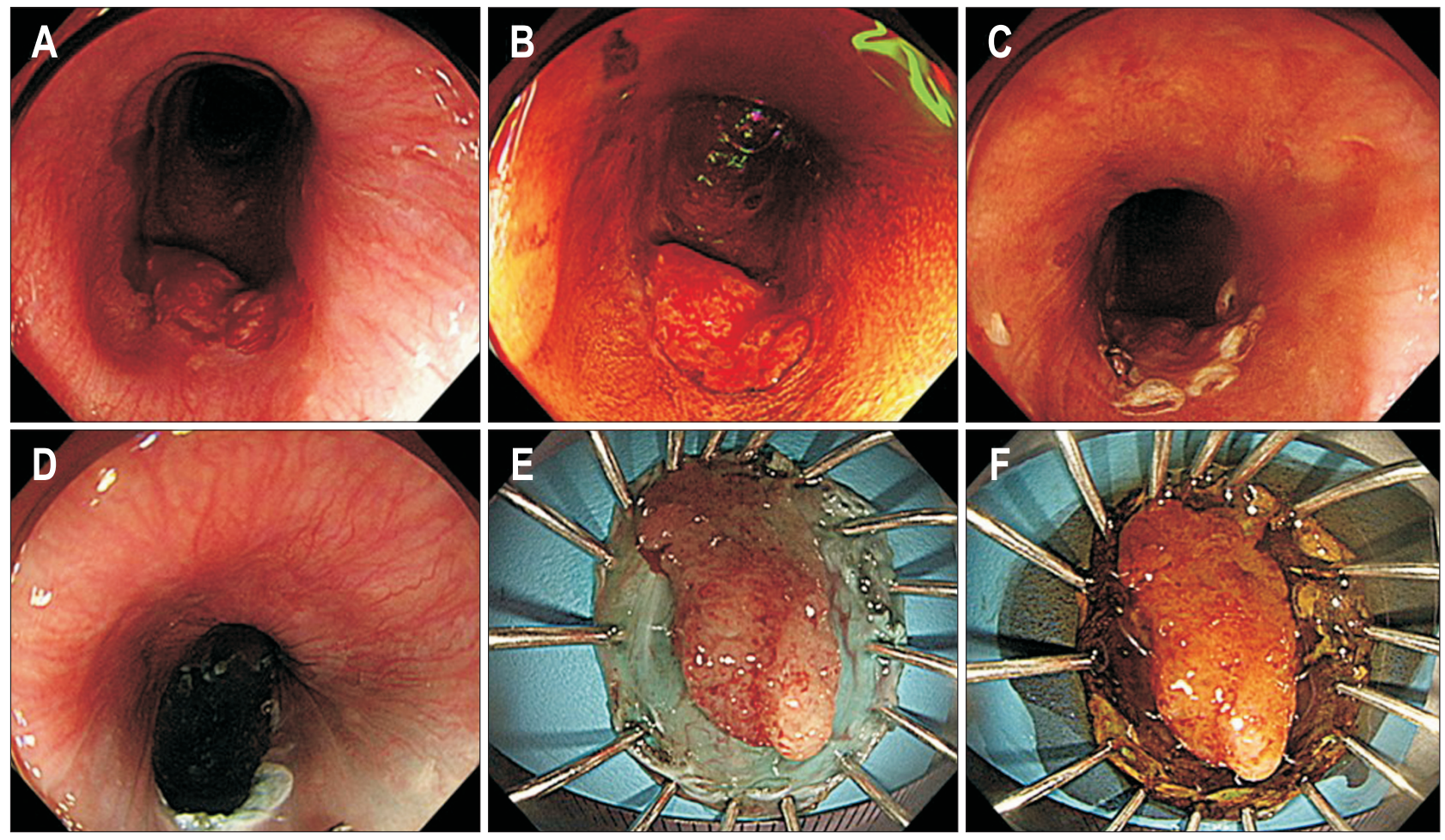

Fig. 2. Endoscopic submucosal dissection of the pyloric gland adenoma. (A) Conventional white-light endoscopy showing the flat, elevated lesion with nodularity. (B) Chromoendoscopy with iodine staining to demarcate the Lugol-void lesion. (C) Marking around the lesion for endoscopic submucosal dissection. (D) Artificial ulcer after submucosal dissection. (E) Resected specimen with the lesion en bloc. (F) Resected specimen with the lesion on chromoendoscopy with iodine staining.

\section{DISCUSSION}

Pyloric gland adenoma was first reported by Elster in $1976 .{ }^{9}$ In 1990, Watanabe et al..$^{10}$ included pyloric gland adenoma in the World Health Organization gastric tumor classification. Cases of pyloric gland adenomas have been reported in the duodenum, ${ }^{2}$ pancreas, ${ }^{3}$ gallbladder, ${ }^{4}$ and uterine cervix. ${ }^{5}$ The literature on the clinicopathologi- cal features of pyloric gland adenomas suggests they are predominantly found in the body of the stomach (64\%), in patients with an average age of 73 years, and in women (75\%). A pyloric gland adenoma is often accompanied by autoimmune atrophic gastritis ( $40 \%$ of cases) and intestinal metaplasia (60\% of cases). ${ }^{5,11}$ Endoscopically, most gastric pyloric gland adenomas appear as polypoid or masslike lesions, although some of them do present as irregular 

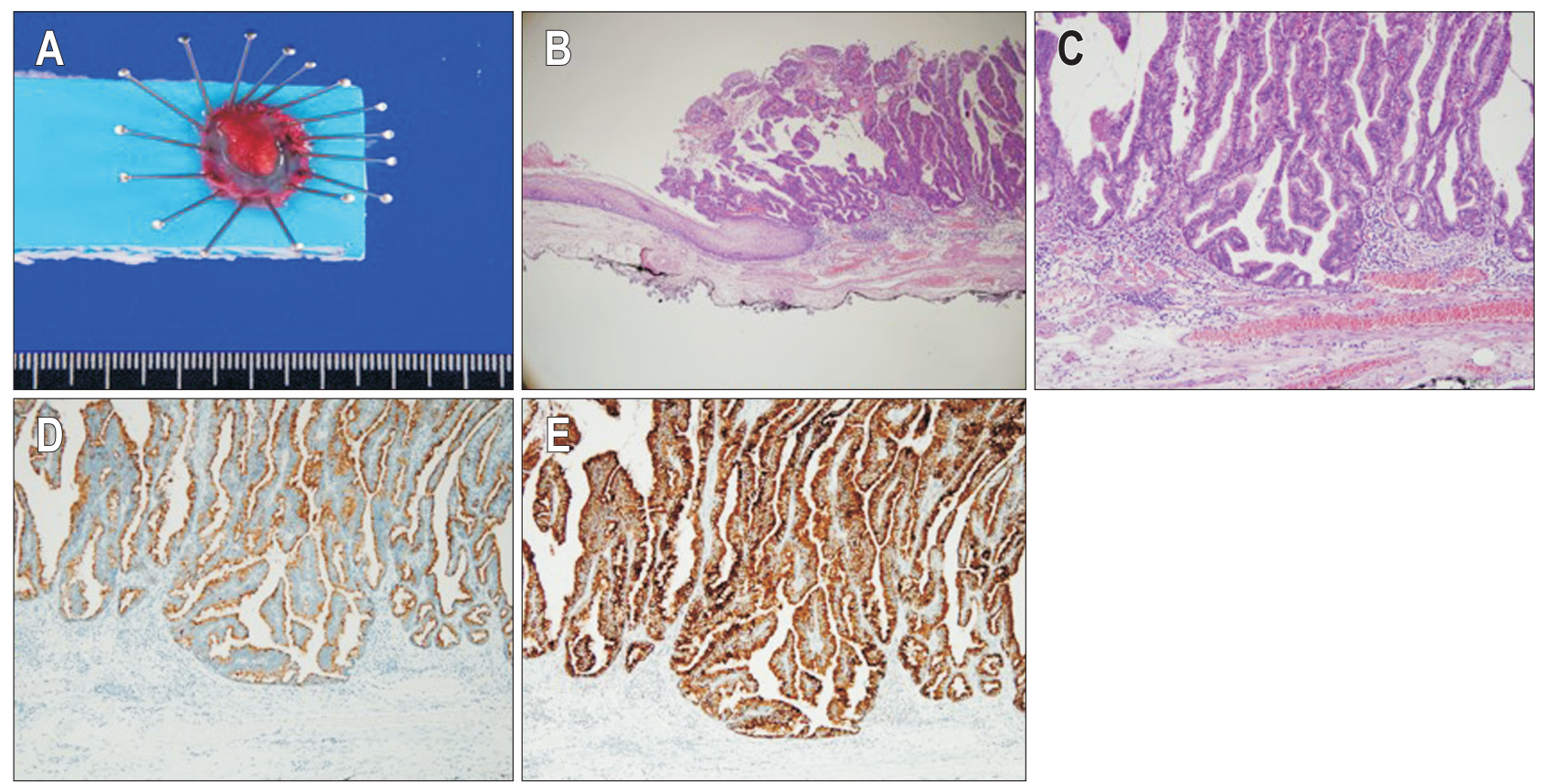

Fig. 3. Gross and histologic findings. (A) Endoscopically dissected specimen showing a $1.1 \times 0.6 \times 0.2 \mathrm{~cm}$-sized lesion. (B) Pyloric gland adenoma with adjacent esophageal mucosa $(H \& E, \times 40)$ (C) Closely packed pyloric-type glands lined by cuboidal to low columnar epithelia with eosinophilic cytoplasm (H\&E, ×100). (D) The superficial layer is predominantly immunopositive for Mucin $6(\times 100)$. (E) Most glands are immunopositive for Mucin $5 A C(\times 100)$.

mucosal, flat, ulcerative, or even submucosal tumor-like lesions. ${ }^{12,13}$ A case report described magnifying endoscopy with narrow-band imaging of a gastric pyloric gland adenoma. On the magnifying endoscopy with narrow-band imaging, a demarcation line and a granular surface structure were noted. Further, both the microvascular and microsurface structures were irregular. ${ }^{14}$ Endoscopic features of esophageal pyloric gland adenomas are not well known. The reported cases of esophageal pyloric gland adenomas have been polypoid, located in the upper or lower esophagus and arising in either Barrett's esophagus or in normal esophageal epithelium. ${ }^{6-8}$ Histologically, a pyloric gland adenoma consists of closely packed cuboidal to low columnar epithelial cells with eosinophilic ground-glass cytoplasm. ${ }^{5,11}$ The nuclei are round and may have no nucleolus. Pyloric gland adenomas are associated with high-grade dysplasia and have a risk of transforming into adenocarcinomas (12\% to $47 \%$ of cases). ${ }^{1}$ Immunohistochemistry is not always required to diagnose pyloric gland adenomas. However, Mucin 6 and Mucin 5AC stains can be used to confirm cases with uncertain diagnoses. ${ }^{1}$ On immunohistochemical examinations, pyloric gland adenomas express Mucin 6 throughout the lesion and its surface, with variable Mucin 5AC expression. Pyloric gland adenomas do not express intestinal markers such as Mucin 2 and CD10 in their pure form. However, pyloric gland adenomas may express $\mathrm{Mu}-$ cin 2 and CD10 when they are transformed from gastric to intestinal type. Pyloric gland adenomas tend to have a higher Ki-67 index when they have an adenocarcinoma component. It is hard to know the exact incidence or predominant site of pyloric gland adenomas in extragastric areas as these adenomas are very rare. Some case reports have described extragastric pyloric gland adenomas in Barrett's esophagus, ${ }^{6}$ heterotrophic gastric mucosa in the rectum, ${ }^{15}$ duodenum, ${ }^{2}$ gallbladder, ${ }^{3}$ and pancreatic duct. ${ }^{4}$ In Korea, only one case of pyloric gland adenoma in the stomach was reported. ${ }^{16}$ To our knowledge, this is the first report of a pyloric gland adenoma in the esophagus in Korea.

\section{CONFLICTS OF INTEREST}

No potential conflict of interest relevant to this article was reported.

\section{AUTHOR CONTRIBUTIONS}

Manuscript drafting: K.P. Literature review: S.D.L. Biopsied tissue examination: H.L. Study supervision and manuscript revision: D.H.K., H.Y.J. All authors read and approved the final manuscript. 


\section{ORCID}

Kwangbeom Park https://orcid.org/0000-0002-3826-3274

Do Hoon Kim https://orcid.org/0000-0002-4250-4683

Sung Duck Lee

Hyun Lee https://orcid.org/0000-0001-9566-9097 https://orcid.org/0000-0001-7005-8142

Hwoon-Yong Jung https://orcid.org/0000-0003-1281-5859

\section{REFERENCES}

1. Vieth M, Kushima R, Mukaisho K, Sakai R, Kasami T, Hattori T. Immunohistochemical analysis of pyloric gland adenomas using a series of Mucin 2, Mucin 5AC, Mucin 6, CD10, Ki67 and p53. Virchows Arch 2010;457:529-536.

2. Kushima R, Rüthlein HJ, Stolte M, Bamba M, Hattori T, Borchard F. 'Pyloric gland-type adenoma' arising in heterotopic gastric mucosa of the duodenum, with dysplastic progression of the gastric type. Virchows Arch 1999;435:452-457.

3. Bakotic BW, Robinson MJ, Sturm PD, Hruban RH, Offerhaus GJ, Albores-Saavedra J. Pyloric gland adenoma of the main pancreatic duct. Am J Surg Pathol 1999;23:227-231.

4. Kushima R, Remmele W, Stolte M, Borchard F. Pyloric gland type adenoma of the gallbladder with squamoid spindle cell metaplasia. Pathol Res Pract 1996;192:963-969.

5. Vieth M, Kushima R, Borchard F, Stolte M. Pyloric gland adenoma: a clinico-pathological analysis of 90 cases. Virchows Arch 2003;442:317-321.

6. Kushima R, Vieth M, Mukaisho K, et al. Pyloric gland adenoma arising in Barrett's esophagus with mucin immunohistochemical and molecular cytogenetic evaluation. Virchows
Arch 2005;446:537-541.

7. Michal M, Curik R, Matler K, Benes Z. Regarding the paper by Vieth et al. Virchows Archiv 442/4:317-321. Virchows Arch 2003;443:589-590.

8. Chlumská A, Waloschek T, Mukenšnabl P, Martínek P, Kašpírková J, Zámečník M. Pyloric gland adenoma: a histologic, immunohistochemical and molecular genetic study of 23 cases. Cesk Patol 2015;51:137-143.

9. Elster K. Histologic classification of gastric polyps. Curr Top Pathol 1976;63:77-93.

10. Watanabe H, Jass JR, Sobin LH. Histological typing of oesophageal and gastric tumours. Berlin: Springer, 1990.

11. Chen ZM, Scudiere JR, Abraham SC, Montgomery E. Pyloric gland adenoma: an entity distinct from gastric foveolar type adenoma. Am J Surg Pathol 2009;33:186-193.

12. Choi WT, Brown I, Ushiku T, et al. Gastric pyloric gland adenoma: a multicentre clinicopathological study of 67 cases. Histopathology 2018;72:1007-1014.

13. Min CC, Wu J, Hou F, et al. Gastric pyloric gland adenoma resembling a submucosal tumor: a case report. World J Clin Cases 2020;8:2380-2386.

14. Togo K, Ueo T, Yonemasu H. Pyloric gland adenoma observed by magnifying endoscopy with narrow-band imaging. Dig Endosc 2014;26:755-756.

15. Vieth M, Kushima R, de Jonge JP, Borchard F, Oellig F, Stolte M. Adenoma with gastric differentiation (so-called pyloric gland adenoma) in a heterotopic gastric corpus mucosa in the rectum. Virchows Arch 2005;446:542-545.

16. Ahn JY, Suh SO, Jung JO, et al. A case of pyloric gland adenoma in the cardia of the stomach, treated by endoscopic submucosal dissection. Korean J Med 2011;80:78-81. 